\title{
As diferenças entre Fichte e Schelling referentes à questão do direito
}

Délia Popa

Tradutor: Cleber Daniel Lambert da Silva

\section{OpenEdition \\ Journals}

\section{Edição electrónica}

URL: http://journals.openedition.org/ref/392

DOI: $10.4000 /$ ref.392

ISSN: 2258-014X

\section{Editora}

EuroPhilosophie Editions

\section{Refêrencia eletrónica}

Délia Popa, "As diferenças entre Fichte e Schelling referentes à questão do direito », Revista de

Estud(i)os sobre Fichte [Online], 3 | 2011, posto online no dia 01 fevereiro 2011, consultado o 08

setembro 2020. URL : http://journals.openedition.org/ref/392 ; DOI : https://doi.org/10.4000/ref.392

Este documento foi criado de forma automática no dia 8 setembro 2020.

(c) EuroPhilosophie 


\title{
As diferenças entre Fichte $\mathrm{e}$ Schelling referentes à questão do direito
}

\author{
Délia Popa
}

Tradução : Cleber Daniel Lambert da Silva

\section{NOTA DO AUTOR}

Traduzido do francês para o português por Cleber Daniel Lambert da Silva, Mestre em Filosofia pela Université de Poitiers.

1 Como se forma a comunidade dos seres livres e o que garante sua estabilidade? Como estabelecemos uma comunidade com os outros? Seria integrando sua alteridade na esfera daquilo que nos é próprio? Seria renunciando àquilo que nos é próprio para aderir ao comum enquanto esfera separada? Ou, então, seria encontrando uma passagem do próprio ao estrangeiro que, reunindo ambos, nos liberaria de ter que escolher entre um e outro? Proponho examinar essas questões, referentes às condições de constituição da subjetividade coletiva, à luz de uma análise da relação que pode ser estabelecida entre as primeiras teorias do direito esboçadas por Fichte e Schelling, quais sejam, respectivamente $O$ Fundamento do Direito Natural segundo os Princípios da Doutrina da Ciência, de 1796-1797, e A Nova Dedução do Direito Natural.

2 Entre os três primeiros escritos filosóficos schellinguianos ${ }^{1}$, a Neue Deduktion des Naturrechts de 1796-1797 ocupa um lugar que ainda não foi suficientemente determinado pela Crítica, em razão de sua natureza inacabada e aporética, da posição ambivalente, jurídica e política, que dela se depreende e da aparente incongruência que ela parece manifestar em face da posição schellinguiana posterior, sobretudo aquela do período da filosofia da identidade ${ }^{2}$. Gostaria de estabelecer a problemática de minha proposta sobre essa ambigüidade do tratado schellinguiano, tendo em vista sublinhar a especificidade da posição de Schelling sobre o direito em relação àquela de Fichte. Com 
efeito, ao invés de insistir nos numerosos pontos em comum entre os dois tratados tais como a crítica do direito natural, a defesa da autonomia do direito em relação à moral, ou ainda as soluções propostas para resolver a difícil relação entre as liberdades individuais - tentarei depreender aqui algumas diferenças que permitem colocar em evidencia o interesse de uma nova leitura do tratado schellinguiano.

Para dar conta da dificuldade do texto schellinguiano de 1796, certas interpretações abordam sua contribuição sobre o direito à luz de uma crise que teria ocorrido no percurso de seu autor: esse texto atestaria, assim, um tateamento do jovem Schelling no terreno jurídico que teria se encerrado com a descoberta do tratado fichteano ${ }^{3}$; ou então, partindo de uma insatisfação diante da solução proposta por Fichte, sua redação não teria sido abandonada senão para permitir a elaboração de uma nova perspectiva sobre o direito no Sistema do Idealismo Transcendental de 1800 e nas obras que lhe sucederam ${ }^{4}$. Sem discutir aqui essas duas teses, eu privilegiarei, no presente texto, uma via interpretativa um pouco diferente, que convida a ler o texto schellinguiano como uma continuidade de seus três primeiros trabalhos, como o último elemento de uma série de quatro etapas ${ }^{5}$, através das quais Schelling prepara seu percurso de pensamento, sem deixar de precisar de maneira progressiva sua relação com Fichte. Se seguirmos essa perspectiva hermenêutica, seu texto sobre o direito pode ser lido como um primeiro passo dado na direção de um distanciamento tomado em relação a Fichte ${ }^{6}$.

\section{0 conflito das liberdades e o direito à coerção}

Definindo o ser racional como o principio de uma ação que se exerce, antes de tudo, sobre ela mesma, Fichte destaca a individualidade desse ser a partir da relação prática que ele entretem com o que excede a esfera do desdobramento incondicional de sua liberdade. Entretanto, essa dimensão do Não-Eu não é um correlato passivo da ação do $\mathrm{Eu}$, mas um princípio que participa do despertar da consciência de si e de sua liberdade prática. Forma que designa geralmente o regime da alteridade, tal princípio compreende o corpo próprio, em seguida os seres que agem obedecendo a leis orgânicas (a liberdade dos outros indivíduos racionais) e, finalmente, aqueles que seguem leis puramente mecânicas (a natureza) ${ }^{7}$. Se as relações que entretemos com essa última forma de alteridade consistem em relações de submissão e de modificação, aquelas que entretemos com a alteridade dos outros homens são relações de ação e de paixão recíprocas que nos determinam em nosso ser e na prática de nossa liberdade; de modo que nós nos descobrimos enquanto seres dispondo de uma atividade movida por uma causalidade própria a partir de um apelo que nos é lançado por um outro ser racional. Se nossa própria racionalidade se revela, enquanto consciência de si, sob o choque da impulsão que uma outra liberdade exerce sobre ela, isso se deve ao fato de que Fichte define, a um só tempo, a atividade individual como "constrita e assujeitada", como materialmente determinada e limitada. Deduzindo a intersubjetividade da posição da atividade livre, Fichte não faz outra coisa a não ser sublinhar a autolimitação à qual deve se submeter esta última, porém descobre, igualmente, a fonte da contingência das relações sociais, que exigem uma regulação fundada no reconhecimento recíproco das liberdades 9 .

5 Para sair da aporia do conflito material das liberdades, é necessário estabelecer uma limitação, garantida pelo direito, da liberdade de cada um pela liberdade de outrem e vice-versa. A comunidade jurídica é, portanto, a expressão da autolimitação de cada 
liberdade em relação às outras liberdades e reúne - atribuindo sua responsabilidade aos éforos ${ }^{10}$ - o exercício da soberania e da força. Se as coisas se passam dessa maneira, isso se deve ao fato de que o acordo juridico que assegura a coexistência pacifica de varias liberdades não saberia repousar sobre o dever moral: "A lei moral comanda categoricamente o dever; a lei juridica nada faz senão permitir que se exerça seu direito, mas não comanda jamais" ${ }^{11}$. Onde a moral exige e sanciona, o direito organiza as possibilidades e fixa as condições que se tornam praticáveis por todos. Assim, o direito busca definir as condições práticas da ação coletiva, ao passo que a moral se contenta em prescrever as obrigações e as coações que derivam dessas condições no nível individual. É por isso que o direito não pode revestir uma forma categórica: seu papel é de preparar as condições das interações que definem uma esfera do comum onde a liberdade de cada um jamais pode ser sacrificada. Entretanto, essa condição positiva da manutenção mútua da liberdade na totalidade da experiência possível justificará a aliança indelével da força e da razão no seio do conceito de direito e legitimará a coerção exercida sobre aqueles que não o respeitam.

$\mathrm{O}$ argumento favorável a essa aliança consiste em dizer que o direito abarca unicamente aquilo que entra na esfera "de uma relação entre seres racionais" ${ }^{12}$, relação que em nada depende da inflexão que suas vontades podem tomar, espontaneamente ou sob a influência de um imperativo moral. Aquilo que interessa ao direito é "a ação recíproca real"13 dos seres racionais, com seu corolário de conseqüências e de reações, cujo alcance concreto deve ser constantemente reavaliado. É dessa maneira que o direito é invocado como garantia da realidade do reconhecimento mútuo dos seres livres, no seio das comunidades práticas. Com efeito, não é unicamente a observação das condições formais que deve ocupar o direito: se a questão das conseqüências das ações livres, num contexto coletivo, apresenta-se agudamente a ele, é porque as condições materiais dessas ações devem ser levadas em conta.

7 Portanto, parece claramente que toda ação se choca com uma resistência, sendo a primeira aquela de nosso próprio corpo, compreendido como aquilo que persiste "de maneira ininterrupta em seu ser"14. Ora, essa resistência não deve ser concebida como aquilo que contraria a liberdade de ação, mas como aquilo que modifica suas condições formais. $\mathrm{O}$ corpo próprio, primeira forma de alteridade encontrada pela ação, é ligado aos outros corpos, o que faz com que nós evoluamos a partir das influências que deles sofremos. Desse modo, parece que a liberdade de outrem não é somente a impulsão (Anstoss) inicial de minha posição egóica e de minha ação, mas igualmente uma "matéria sutil" ${ }^{15}$ sobre a qual eu posso agir através da simples força (da mesma maneira que o outro pode agir sobre minha própria liberdade). É essa ambigüidade do estatuto da liberdade, ao mesmo tempo referência à liberdade de outrem e suporte da potência cega da força, que reveste o direito de sua especificidade negativa ${ }^{16}$.

o desafio que representa a introdução do direito consiste, pois, em limitar o exercício da força, através da lei, a qual se apóia sobre o principio racional da reciprocidade das liberdades. Entretanto, o direito se apresenta como uma "primeira forma de alienação" ${ }^{17}$, à qual a liberdade deve se submeter em nome de sua duração no tempo e de sua coerência na totalidade da experiência vindoura. Contrariamente aos princípios morais que apresentam uma aplicabilidade universal, o direito ocupa-se somente destas situações onde o princípio da reciprocidade das liberdades corre o risco de ser transgredido. Nesse caso, ele é entendido como direito de coação que recai sobre aquele que não reconhece sua validade, a fim de restabelecer com ele uma comunidade 
racional ${ }^{18}$. Assim, a lei jurídica é o elemento que garante o caráter durável da partilha da liberdade, remetendo todo ato às suas consequiências e se apresentando como remédio para a contingência da ação do outro.

\section{A auto-afirmação múltipla da liberdade}

9 Onde Fichte buscava dar conta do caráter prático da intuição teórica, descrevendo-a como um princípio de ação, Schelling concebera a filosofia prática como um complemento positivo da filosofia teórica ${ }^{19}$, cuja abordagem objetivante impõe limites e obstáculos à afirmação incondicional da liberdade. O domínio da filosofia prática é, conseqüentemente, compreendido como aquele do exercício imanente da liberdade, que procura realizar sua incondicionalidade "através de uma prática infinita" ${ }^{20}$.

10 Assim como em Fichte, a individuação da liberdade inicia-se sob a influência de um encontro com outra liberdade: trata-se da heteronomia do autônomo, a qual se distingue da heteronomia do heterônomo, que se refere à natureza entendida como conjunto de leis mecânicas. Porém, essa dupla forma de manifestação da heteronomia não desemboca num dualismo entendido no sentido estrito, razão pela qual o esforço de realização da liberdade não poderá ser assegurado aqui por um pacto entre a ordem incondicional do racional e o jogo cego das forças físicas. A força, que Schelling compreende como potência, participa do movimento de afirmação da liberdade, o qual não pode ser suprimido, mas somente "desviado" por uma inversão interna ${ }^{21}$. Uma vez que a alienação da liberdade faz parte das possibilidades intrínsecas do desenvolvimento de seu movimento, não é uma nova forma - exterior e contratual ${ }^{22}$ de alienação que poderá evitá-la ou suspendê-la, mas um trabalho ativo sobre os condicionamentos internos que impedem sua afirmação.

11 A realização do incondicionado, que cabe à liberdade, passa por um esforço (Streben) empírico que contradiz necessariamente outros esforços empíricos ${ }^{23}$. Ora, a finalidade da aspiração moral consiste em encontrar no outro um "sujeito co-atuante" ${ }^{24}$, em entrar, pois, com ele em uma relação de reciprocidade que ultrapassa a necessidade mecânica da coerção. Para resolver esse problema, a filosofia moral exige uma renúncia à liberdade empírica individual em nome da liberdade absoluta ou geral. Limitada às recomendações que concernem à consciência individual, ela não dá conta do funcionamento real da comunidade que esta última forma com as outras liberdades. Porém, antes de reconhecer a pertinência do direito nesse domínio, Schelling realça os problemas próprios à ética, compreendida como terreno de constituição negativa da comunidade das liberdades, que labuta para garantir, por sua vez, a ipseidade de cada indivíduo no seio da comunidade. É para responder a essa exigência, que não pode ser satisfeita no terreno da ética, que será introduzida a função positiva do direito, afirmando a individualidade da vontade segundo sua forma, lá onde a moral exigia seu sacrifício segundo sua matéria ${ }^{25}$. Essa distinção entre as duas dimensões da vontade deslocará o desafio da questão jurídica na direção de uma afirmação do princípio incondicional da liberdade contra todo sistema factual de coerção que, longe de fornecer uma garantia à liberdade, entrava seu desdobramento natural.

Entre o domínio prático da moral e o domínio teórico da possibilidade, o direito se institui em um ponto de articulação que remete as ações aos seus princípios, ao mesmo tempo em que acorda a elas uma forma de realização que leva em conta a ipseidade do agente que garante sua concretização. Dessa maneira, seu papel não se limita à menção 
da pura possibilidade dos princípios da liberdade: é a realização desses princípios que ocupa o direito, explorando "uma possibilidade prática (praktische Möglichkeit)"26 que não será jamais categórica, mas problemática. Assim, à irresolução negativa da ética corresponde a irresolução positiva do direito, pois da mesma maneira que a ética realça a impossibilidade de identificar a liberdade individual à liberdade universal, o direito destaca a dificuldade de identificar a liberdade universal à liberdade individual ${ }^{27}$. Portanto, suas tarefas conjuntas constituem o tema de um trabalho contínuo e o que aparece como inconcebível no nível teórico - a identificação, nos dois sentidos, da vontade singular e da vontade universal - torna-se a finalidade de uma prática infinita, que busca vias de engendramento do comum a partir da afirmação das ipseidades. É por isso que o direito será compreendido por Schelling como aquilo que afirma a vontade individual, contra a vontade universal ou em igual oposição às outras vontades ${ }^{28}$.

A coerção, compreendida como esforço externo (físico) ou interno (psicológico) que tende a suprimir a ipseidade da vontade, é aquilo contra o que a vontade individual deve, portanto, defender-se. Efeito de uma heteronomia desvinculada de todo exercício da autonomia, ela surge de uma relação de objetivação que oculta a auto-afirmação prática da liberdade. Um direito que consiste nessa relação é regido por "puras leis naturais" 29 , e Schelling pretende ultrapassá-lo para definir um direito "a toda ação pela qual eu salvo a ipseidade de minha vontade" ${ }^{30}$, recordando que a forma da vontade individual não pode ser condicionada por qualquer coisa que lhe seja exterior.

\section{A oponibilidade das liberdades}

Parece, portanto, que Fichte e Schelling não partilham, em 1796, a mesma concepção do direito natural que eles submetem às suas respectivas críticas: lá onde Fichte o compreende como direito originário a uma liberdade individual infinita, uma ficção teórica que não pode encontrar aplicabilidade prática ${ }^{31}$, Schelling o concebe como força puramente mecânica ${ }^{32}$ que ameaça a liberdade incondicional enquanto forma da vontade. Colocando as bases de uma nova teoria do direito, os dois autores perseguem, dessa maneira, objetivos diferentes, quase opostos. Para Fichte, o direito não pode ser concebido como "direito de pensar ou de querer livremente", mas unicamente como "um direito de conservação sensível de si" ou ainda como "direito de coerção contra aquele que nos agride através de nosso corpo" ${ }^{33}$ - determinação do direito que Schelling procura ultrapassar para legitimar uma liberdade entendida como auto-produção e auto-potenciação ${ }^{34}$.

15 A diferença entre as duas concepções de liberdade, assim elaboradas, não é unicamente aquela entre uma liberdade positiva, que busca se encarnar na historia para poder ser vivida $^{35}$ e uma liberdade negativa, que o direito deve assentar na duração, entre uma liberdade cuja forma é imanente à matéria e uma liberdade cuja materialidade pode se voltar contra a condição formal para suprimi-la, mas também entre uma liberdade que se efetua a cada vez na imediatidade e uma liberdade cuja realização não pode ser confirmada a não ser no porvir. No primeiro caso, trata-se de um princípio prático de auto-afirmação que busca se desdobrar em cada momento da ação humana; no segundo, de um princípio de coerência da experiência, que deve encontrar suas verificações no tempo total de uma existência, que nenhum momento preciso pode garantir inteiramente. 

"necessidade semelhante a um mecanismo, esvaziando absolutamente toda possibilidade de exceção" ${ }^{\text {"3 }}$. Os problemas próprios à afirmação da liberdade, nesse domínio da finitude em que consiste o mundo, são assim resolvidos por um apelo às leis da necessidade, que intervêm para garantir o movimento de auto-limitação das vontades individuais. Perguntar se a auto-limitação não consegue encontrar uma motivação que seja interna à realização individual da liberdade equivale a questionar o pertencimento da solução fichteana à filosofia prática. da filosofia prática resulta de uma contribuição no campo da filosofia prática pela razão teórica, que define nossas relações de objetivação do domínio da natureza, compreendida como conjunto de leis mecânicas. Entretanto, a questão da realização prática da liberdade nos introduz numa outra perspectiva, a saber, aquela das ações e dos usos comuns pelos quais a afirmação dos possíveis acaba por ser transformada. A ética e o direito são as duas expressões dessa filosofia prática em esboço, a primeira por tematizar a constituição do domínio do comum, o segundo por reconhecer uma dimensão ipséica ${ }^{37}$ e dinâmica. Dessa maneira, a fase intermediária da ética, que trata da afirmação da autonomia no regime qualitativamente diversificado da heteronomia, permite, em seguida, pensar positivamente a constituição da comunidade como decisão e ação partilhadas e não apenas negativamente, como segurança recíproca ${ }^{38}$.

Assim, parece que a forma universal da liberdade, à qual devem ser remetidas tanto a vontade comum quanto a individual, deve ser pensada a partir do esforço (Streben) de cada vontade e da resistência (Widerstand) pela qual ela experimenta toda forma de alteridade. A auto-limitação da liberdade aparecerá, a partir disso, como solidária de sua oponibilidade (Entgegenstreben) a partir da resistência, resultado de um processo de aprendizagem prático em que ela afirma sua ipseidade. Um despertar para a heteronomia que torna possível o exercício da autonomia, a resistência pode, entretanto, ser considerada também como condição empírica negativa da invasão das liberdades, que impõe a necessidade da coerção. Porém, essa condição negativa da resistência encontra seu correlato em sua condição positiva, graças à qual a passividade se converte em atividade e a necessidade em espontaneidade ${ }^{39}$, e pela qual as comunidades de ação traduzem a prova da reciprocidade das liberdades. Daquele que é autônomo a um outro autônomo, um pacto de aprendizagem mútua é, então, estabelecido, em uma reflexividade do ato onde o comum se reinventa.

Portanto, a resistência afirma uma outra necessidade que não aquela das leis mecânicas, qual seja, aquela da abertura de um espaço de reflexividade do comum, cuja coerção da força, longe de assegurar sua manutenção, vem aniquilar a possibilidade. Simone Weil escreveu em 1938: "aquele que possui a força caminha num meio sem resistência, sem que nada, na matéria humana em torno dele, tenha a capacidade de suscitar entre o elã e o ato esse breve intervalo onde repousa o pensamento. Onde o pensamento não tem lugar, nem a justiça nem a prudência encontram o seu" ${ }^{40}$.

Revista de Estud(i)os sobre Fichte, 3 | 2011 


\section{NOTAS}

1. Ver F. W. J. schelling, Premiers écrits, tr. J.-F. Courtine, Paris, PUF/Epiméthée, 1987. Os textos de Fichte, aos quais Schelling parece estar se referindo particularmente, são a Doctrine de la science de 1794 e o Précis de ce qui est propre à la Doctrine de la science au point de vue de la faculté théorique de 1795.

2. Cf. Trata-se, sobretudo, das Leçons sur la méthode des études académiques (1803) e do Système de toute philosophie (1804). Essa divergência de perspectivas no percurso de Schelling é destacada por RIVELAYGUE, Schelling et les apories du droit dans Schelling. Cahiers de philosophie politique, $\mathrm{n}^{\circ} 1 / 1983$, Bruxelles, Ousia, 1983, pp. 15-16 e sublinhada por F. FISCHBACH em seu artigo "La pensée politique de Schelling" em: Les études philosophiques, $n^{\circ} 56 / 2001$, pp. 31-48.

3. Ver, nesse sentido, X. TILLIETTE, Une introduction à Schelling, Paris, Honoré Champion, 2007, p. 26.

4. Cf. J. Rivelaygue, Schelling et les apories du droit em Schelling. Cahiers de philosophie politique, pp. 15-16.

5. Essa via hermenêutica foi proposta pelo professor M. Maesschalck em seu curso ministrado na Université Catholique de Louvain durante o ano acadêmico de 2008-2009 sobre a Nouvelle déduction de Schelling.

6. Sobre os detalhes da distância progressiva que se instaura entre Fichte e Schelling ver Correspondance (1794-1802), tr. M. Bienenstock, Paris, PUF/Epiméthée, 1991. Ver também A. SCHNELL, Du système de l'idéalisme transcendantal à la Darstellung : la correspondance Schelling-Fichte, Documentos de trabalho do Seminário Schelling/Fichte nos Arquivos Husserl, Paris, 2008-2009.

7. Para essa distinção ver J. G. FICHTE, Conférences sur la destination du savant, tr. fr. J.-L. Vieillard-Baron, Paris, Vrin, 1969, p. 47.

8. J. G. FICHTE, Fondement du droit naturel, tr. fr. A. Renaut, Paris, PUF/Quadrige, 1984, p. 35. Itálico no texto.

9. J. G. FICHTE, Fondement du droit naturel, pp. 61-62.

10. J. G. FICHTE, Fondement du droit naturel, p. 116.

11. J. G. FICHTE, Fondement du droit naturel, p. 69. O itálico é nosso.

12. J. G. FICHTE, Fondement du droit naturel, p. 69.

13. J. G. FICHTE, Fondement du droit naturel, p. 70.

14. J. G. FICHTE, Fondement du droit naturel, p. 75.

15. J. G. FICHTE, Fondement du droit naturel, p. 85.

16. Essa ambiguidade foi explorada por HEGEL na crítica que ele endereça a Fichte em seu curso sobre a Différence des systèmes philosophiques de Fichte et de Schelling, tr. fr. M. Méry, Paris, Vrin, 1952, p. 130 sq.

17. HEGEL, Différence des systèmes philosophiques de Fichte et de Schelling, p. 119.

18. Assim compreendido, ele "legitima aquele que tenha sido tratado contrariamente ao direito a tratar arbitrariamente o agressor" (HEGEL: Différence des systèmes philosophiques de Fichte et de Schelling, p. 106). Fichte estabelece, entretanto, uma estrita dependência desse direito de coerção em relação ao direito de julgar racionalmente e sublinha a distinção que deve ser feita entre o direito de coerção que pertence à esfera 
jurídica e o dever de coerção que é próprio da esfera moral (HEGEL: Différence des systèmes philosophiques de Fichte et de Schelling,, pp. 110-111).

19. "O que eu não posso realizar teoricamente, eu devo realizá-lo praticamente", cf. F. W. J. SCHELLING, Nouvelle déduction du droit naturel, tr. fr. S. Bonnet e L. FERRY nos Cahiers de philosophie politique, $\mathrm{n}^{\circ} 1 / 1983$, Bruxelles, Ousia, 1983, \$1, p. 96.

20. F. W. J. scheLLING, Nouvelle déduction du droit naturel, \$16, p. 99.

21. A inversão interna do movimento da existência a partir de seu fundo de potência será descrita nas Conférences de Stuttgart como a origem do mal, no qual desaparece "tudo que é natural". F. W. J. schelLiNG, OEuvres métaphysiques, tr. fr. J.-F. Courtine e E. Martineau, Paris, Gallimard/nrf, 1980, p. 244.

22. Às teorias do contrato, que procuram oferecer uma garantia contra a eventual intromissão das liberdades individuais, Schelling opõe, numa longa nota de seu tratado, a ideia segundo a qual a vontade não pode ser determinada, pois ela "escapa infinitamente" a toda objetivação. Assim, todo pacto que quisesse fixar a afirmação da liberdade, através de vontades diferentes, exigiria "uma seqüência infinita de contratos, onde cada um confirmaria o precedente, porém necessitaria de uma nova confirmação". Cf. F. W. J. schelLing, Nouvelle déduction du droit naturel, la note du § 85, p. 111.

23. "Uma atividade empírica sem limites em um estabelece uma passividade sem limites em outro". F. W. J. schelLING, Nouvelle déduction du droit naturel, § 25, p. 100.

24. F. W. J. schelLING, Nouvelle déduction du droit naturel, \$45, p. 104.

25. A forma da vontade individual, destacada pelo direito, liga-se ao que eu sou (uma liberdade que busca realizar o incondicional) e a quem eu sou (um indivíduo confrontado a outros indivíduos que realizam diferentemente o mesmo princípio), ao passo que a matéria da vontade individual é constituída por aquilo que esta última realiza empiricamente, pelas consequiências de suas ações e por suas obras, a saber, todo um domínio que escapa à intuição de si e que é submetido aos riscos da evolução natural e dos agenciamentos automáticos. Sobre o desenvolvimento dessa alteridade mecânica, sobre a alienação que ela exerce sobre o espírito e sobre as consequiências jurídicas dessa ação, ver J. RIVELAYGUE, Schelling et les apories $d u$ droit, p. 58 sq.

26. F. W. J. SCHELLING, Nouvelle déduction du droit naturel, § 61, p. 107. Sublinhado no texto.

27. F. W. J. SCHELLING, Nouvelle déduction du droit naturel, § 72, p. 109.

28. Cf. F. W. J. schelLing, Nouvelle déduction du droit naturel, § 140, p. 120. Trata-se da liberdade moral e da igualdade formal, às quais se soma o direito absoluto que a liberdade individual possui sobre o domínio do heterônomo, a saber, o mundo dos fenômenos, dos objetos e das coisas, que define o direito natural no sentido estrito. Nesse caso, Schelling opõe-se abertamente a Fichte, para quem não pode haver direito, nesse domínio, a não ser em relação com as outras liberdades racionais. Cf. sobre esse ponto J. G. FICHTE, Fondement du droit naturel, p. 69.

29. F. W. J. SCHELLING, Nouvelle déduction du droit naturel, § 161, p. 126.

30. F. W. J. SCHELLING, Nouvelle déduction du droit naturel, § 141, p. 123.

31. J. G. FICHTE, Fondement du droit naturel, p. 127 sq.

32. F. W. J. SCHELLING, Nouvelle déduction du droit naturel, § 161, p. 126.

33. J. G. FICHTE, Fondement du droit naturel, p. 127. Sublinhado no texto. 
34. Essa concepção da liberdade será defendida no Le système de l'idéalisme transcendantal, tr. fr. C.Dubois, Louvain, Peeters, 1978, p. 176 sq.

35. Sobre esse ponto, ver M. MAESSCHALCK, L'anthropologie politique et religieuse de Schelling, Paris, Vrin/Louvain, Peteers, 1991, p. XV sq.

36. J. G. FICHTE, Fondement du droit naturel, p. 153.

37. NT, no original: "ipséique".

38. Sobre essa segunda concepção, ver J. G. FICHTE, Fondement du droit naturel, p. 164 sq.

39. Sobre essa concepção da resistência, ver F. PROust, De la résistance, Paris, Cerf/Passages, 1997, p. 21 sq.

40. S. WEIL, L'Iliade ou le poème de la force dans OEuvres, Paris, Gallimard/Quarto, 1999, p. 537.

\section{RESUMOS}

The paper explores some problems of the theory of law's foundation in German idealism, by comparing Schelling's perspective in his early work of 1796-1797 with Fichte's perspective in his first treatise on law. Despite of the similarities between the two works, some differences may be shown, which underline young Schelling's originality. When criticizing, like Fichte, the natural law, Schelling proposes a new theory on the relation between autonomy and law, opening the aria of thinking a collective subjectivity. Analyzing the practical status of an "autonomous heteronomy" in a relation of equality, his treatise marks a major step in thinking the law as a common right.

\section{ÍNDICE}

Keywords: law, autonomy, collective subjectivity, Fichte, Schelling

\section{AUTORES}

DÉLIA POPA

$\mathrm{UCL} / \mathrm{CPDR}$ 